\title{
Chronic Brucellosis in Japan
}

\author{
Naoki Kawakami ${ }^{1}$, Yoko Wakai ${ }^{1}$, Kazuhito Saito ${ }^{1}$ and Koichi Imaoka ${ }^{2}$
}

\begin{abstract}
:
Human brucellosis, one of the most common zoonoses worldwide, rarely occurs in Japan, and only a few chronic cases have been reported. We herein report the case of a 39-year-old Japanese woman with chronic human brucellosis, considered a Brucella canis infection, that persisted for 19 years. Her medical history and fever pattern suggested chronic brucellosis, and the diagnosis was made based on the results of a serum tube agglutination test (SAT). After undergoing combination therapy with streptomycin and doxycycline, she achieved symptomatic relief and showed negative SAT results. Even in non-endemic areas, chronic brucellosis is an important differential diagnosis in patients with long-term persistent fatigue or a fever.
\end{abstract}

Key words: chronic brucellosis, undulant fever, intermittent fever, chronic fatigue, Brucella canis

(Intern Med 58: 3179-3183, 2019)

(DOI: 10.2169/internalmedicine.2961-19)

\section{Introduction}

Human brucellosis is one of the most common zoonoses worldwide and is considered a serious public health problem, particularly in low-income countries throughout Africa, South America, Asia, and parts of Europe (1). However, brucellosis is extremely rare in Japan, with only two to four cases reported each year (2). Symptoms of human brucellosis are various and nonspecific; thus, the diagnosis is challenging, especially in non-endemic areas, such as Japan. Patients with acute and chronic brucellosis may present with intermittent fever and, in chronic disease, with general malaise or psychoneurosis (3). We herein report a case of chronic brucellosis in Japan - presumed to be a Brucella canis infection - with a 19-year disease duration.

\section{Case Report}

In 2016, a 39-year-old Japanese woman was referred to our hospital with complaints of a persistent high fever for 1 week. Her medical history revealed a long medical narrative.

In 1996, at 18 years of age, she had attended an animal care school and assisted in delivering dogs. In 1998, at 20 years of age, she developed an intermittent nocturnal high fever persisting for 1 month and left arm paralysis and was admitted to our hospital. The paralysis was diagnosed as indeterminate radiculopathy. Her high fever and paralysis spontaneously resolved a few days after admission, so she was discharged on hospital day 10. However, the low-grade fever and slight malaise persisted, and she developed an intermittent night fever $\left(>38^{\circ} \mathrm{C}\right)$ at irregular intervals, ranging from 2 weeks to 6 months. At the highest frequency, her fever without focal symptoms occurred every other week for several months. She was usually diagnosed with common colds because her high fever usually resolved spontaneously within a few days and her malaise during the fever was mild. However, upper respiratory symptoms were only rarely observed in any of these febrile episodes.

In May 2014, at 37 years of age, she visited another hospital due to complaints of a high fever for 1 week. Blood cultures were negative; however, whole-body computed tomography (CT) revealed mediastinal and abdominal lymph node swelling (Fig. 1). Symptoms, physical examination results, and blood test results were all nonspecific. In addition, the results of the QuantiFERON TB-3G $\mathrm{G}^{\circledR}$ test were negative. She was prescribed oral garenoxacin (GRNX) tablets at 400 $\mathrm{mg} /$ day without a diagnosis. Her body temperature decreased a few days after taking GRNX. However, the high fever recurred after discontinuing the medication. She was repeatedly prescribed GRNX, and the fever abated each time she took the medication and recurred when she stopped. Fi-

${ }^{1}$ Department of Respiratory Medicine, Tsuchiura Kyodo Hospital, Japan and ${ }^{2}$ Laboratory of Reservoir Control of Zoonosis, Department of Veterinary Science, National Institute of Infectious Diseases, Japan

Received for publication March 9, 2019; Accepted for publication May 13, 2019

Correspondence to Dr. Naoki Kawakami, knaoki0321@ @otmail.co.jp 

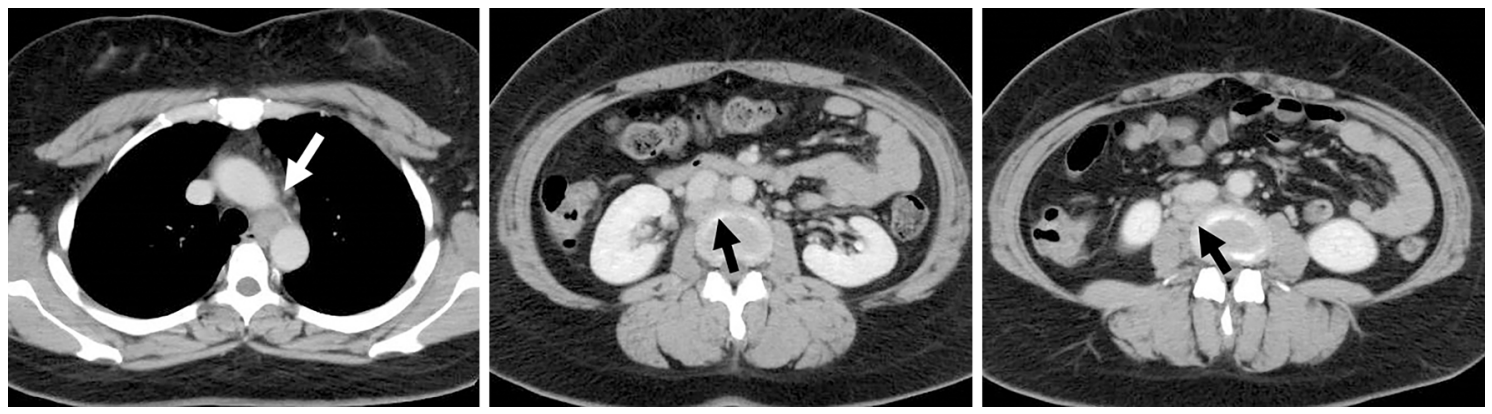

Figure 1. Whole-body computed tomography in 2014 showing mediastinal and abdominal lymph node swelling (arrows).

Table. Peripheral Blood Test on the Last Admission.

\begin{tabular}{|c|c|c|c|c|c|}
\hline Hematology & & Biochemistry & & Serology & \\
\hline WBC & $8,120 / \mu \mathrm{L}$ & TP & $7.8 \mathrm{~g} / \mathrm{dL}$ & HBs antigen & Negative \\
\hline Neutrophils & $77.4 \%$ & Alb & $3.9 \mathrm{~g} / \mathrm{dL}$ & HCV antibody & Negative \\
\hline Lymphocytes & $15.0 \%$ & BUN & $10 \mathrm{mg} / \mathrm{dL}$ & HIV screening test & Negative \\
\hline Monocytes & $6.7 \%$ & $\mathrm{Cr}$ & $0.70 \mathrm{mg} / \mathrm{dL}$ & RPR (Quantitative) & Negative \\
\hline Eosinophils & $0.7 \%$ & UA & $4.8 \mathrm{mg} / \mathrm{dL}$ & TPHA (Quantitative) & Negative \\
\hline Basophils & $0.2 \%$ & $\mathrm{Na}$ & $134 \mathrm{mEq} / \mathrm{L}$ & T-Spot $\mathrm{TB}^{\circledR}$ & Negative \\
\hline $\mathrm{Hb}$ & $14.0 \mathrm{~g} / \mathrm{dL}$ & $\mathrm{K}$ & $3.9 \mathrm{mEq} / \mathrm{L}$ & EBV-VCA IgG (EIA) & 4.5 index \\
\hline Plt & $27.1 \times 10^{4} / \mu \mathrm{L}$ & $\mathrm{Ca}$ & $8.8 \mathrm{mg} / \mathrm{dL}$ & EBV-VCA IgM (EIA) & Negative index \\
\hline \multirow[t]{2}{*}{ ESR } & $52 \mathrm{~mm}$ & AST & $31 \mathrm{IU} / \mathrm{L}$ & EBV-EBNA IgG (EIA) & 2.5 index \\
\hline & & ALT & $55 \mathrm{IU} / \mathrm{L}$ & EBV-EA IgG (EIA) & 1.4 index \\
\hline Immunology & & LDH & $267 \mathrm{IU} / \mathrm{L}$ & EBV-DNA & Negative \\
\hline ANA & $\leq \times 20$ & ALP & $135 \mathrm{IU} / \mathrm{L}$ & CMV IgG & Negative \\
\hline $\mathrm{RF}$ & $6 \mathrm{IU} / \mathrm{mL}$ & $\gamma$-GTP & $31 \mathrm{IU} / \mathrm{L}$ & CMV IgM & Negative \\
\hline CH50 & $46.3 \mathrm{U} / \mathrm{mL}$ & T-Bil & $0.7 \mathrm{mg} / \mathrm{dL}$ & Toxoplasma $\mathrm{IgG}$ & Negative \\
\hline PR3-ANCA & Negative & CK & $50 \mathrm{IU} / \mathrm{L}$ & Toxoplasma IgM & Negative \\
\hline MPO-ANCA & Negative & Glu & $134 \mathrm{mg} / \mathrm{dL}$ & SAT for Brucella abortus & $<1: 40$ \\
\hline $\operatorname{IgG}$ & $1,505 \mathrm{mg} / \mathrm{dL}$ & $\mathrm{HbA1c}$ & $6.0 \%$ & SAT for Brucella canis & $1: 160$ \\
\hline $\operatorname{IgA}$ & $236 \mathrm{mg} / \mathrm{dL}$ & CRP & $13.66 \mathrm{mg} / \mathrm{dL}$ & soluble IL-2 receptor & $535 \mathrm{U} / \mathrm{mL}$ \\
\hline $\operatorname{IgM}$ & $101 \mathrm{mg} / \mathrm{dL}$ & Procalcitonin & $0.18 \mathrm{ng} / \mathrm{mL}$ & & \\
\hline $\operatorname{IgE}$ & $862 \mathrm{IU} / \mathrm{mL}$ & Ferritin & $211 \mu \mathrm{g} / \mathrm{mL}$ & & \\
\hline
\end{tabular}

ESR: erythrocyte sedimentation rate, ANA: antinuclear antibodies, RF: rheumatoid factor, CH50: 50\% hemolytic complement activity, MPO: myeloperoxidase, PR3: proteinase-3, ANCA: antineutrophil cytoplasmic antibody, RPR: rapid plasma reagin, TPHA:Treponema pallidum hemagglutination test, EBV: Epstein-Barr virus, VCA: virus capsid antigen, EA: early antigen, CMV: cytomegalovirus, SAT: serum agglutinin test, IL-2: interleukin-2

nally, after receiving $1 \mathrm{~g}$ of oral azithromycin in addition to GRNX, the high fever subsided and did not recur after discontinuing the medication. She discontinued the follow-up visits. Ever after the high fever subsided, she still experienced a low-grade fever and slight malaise, and a high fever recurred at irregular intervals after several months.

In August 2016, at 39 years of age, she developed a persistent high fever with general arthralgia, headache, nausea, and vomiting. Subsequently, she was referred and admitted to our hospital. She had a history of cough-variant asthma but was not taking any medications, illegal drugs, or herbal supplements. She had had one pregnancy and delivered the baby via normal birth. She had no history of abortion. She never smoked and only drank occasionally. She worked as a courier delivering bread and had not traveled overseas. She had owned a Pomeranian dog from 1999 to 2015 and an- other since July 2016. As previously mentioned, her first febrile illness occurred in 1998 while attending an animal care school.

Her vital signs upon admission were as follows: body temperature, $37.5^{\circ} \mathrm{C}$; blood pressure, $116 / 80 \mathrm{mmHg}$; pulse rate, $109 \mathrm{bpm}$; respiratory rate, 12/min; and oxygen saturation, $98 \%$ (on room air). She was mildly weak but conscious; the results of physical examination were unremarkable. Laboratory tests showed the following results: white blood cell count, $8,120 / \mu \mathrm{L}$ ( $77 \%$ neutrophils); hemoglobin level, $14.0 \mathrm{~g} / \mathrm{dL}$; and platelet count of $271,000 / \mu \mathrm{L}$. Her Creactive protein level was elevated $(13.66 \mathrm{mg} / \mathrm{dL})$. HIV screening and T-Spot $\mathrm{TB}^{\circledR}$ test results were negative (Table). Results of transthoracic echocardiography and head CT were normal. Results of whole-body CT were also normal; furthermore, the mediastinal and abdominal lymph node swel- 


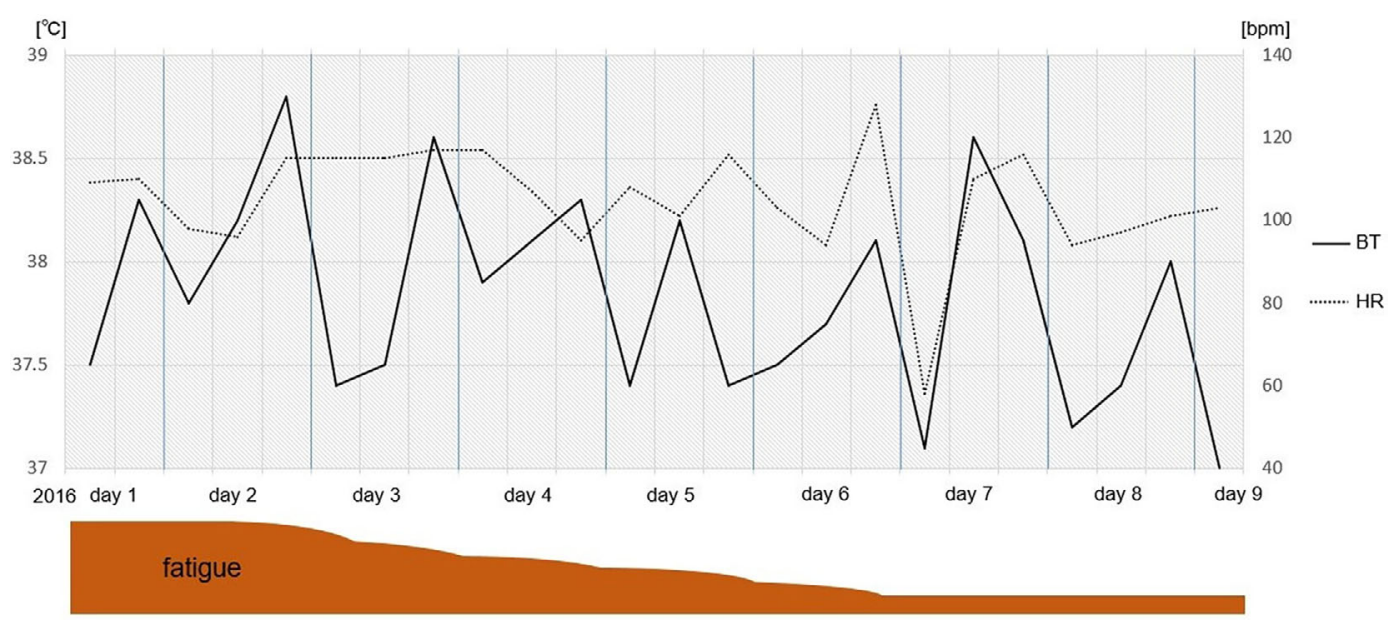

headache \& nausea

general arthralgia

Figure 2. Fever pattern at the last admission showing an intermittent nocturnal fever. Only cooling treatment was provided. No antipyretic or antibiotics were administered.

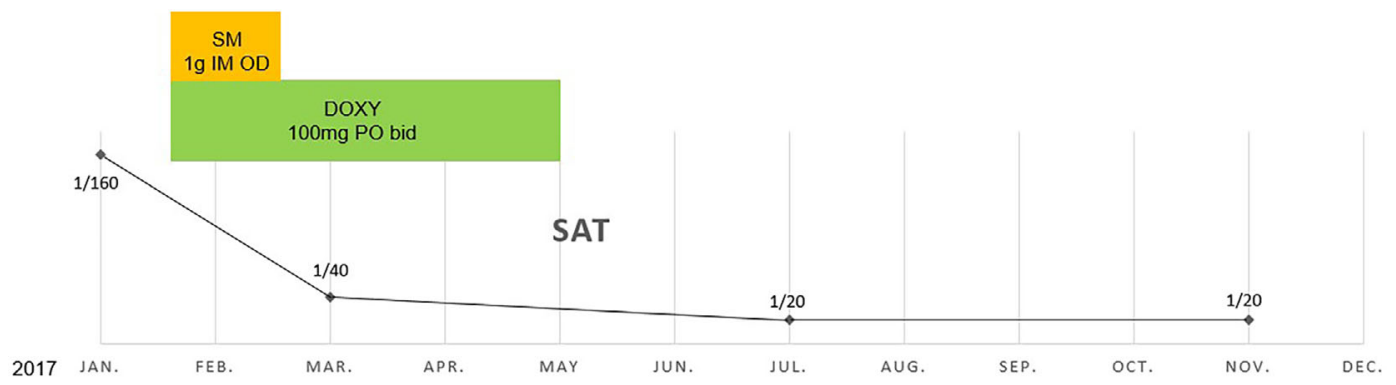

Fatigue

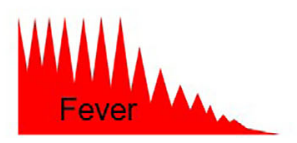

Figure 3. The clinical course and serum agglutination test (SAT) titers for Brucella canis after treatment initiation.

ling noted in 2014 had decreased. Gallium-67 scintigraphy showed no focal uptake. Urinalysis and cerebrospinal fluid test results were normal, and blood culture results were negative.

She frequently experienced a nocturnal fever (Fig. 2). Several days after admission, her fever and other symptoms resolved spontaneously. Her history of close contact with dogs and fever pattern suggested brucellosis. We therefore performed the serum tube agglutination test (SAT) for Brucella. SAT results were positive for $B$. canis (1:160) and negative for $B$. abortus (<1:40) (Table). Therefore, a diagnosis of chronic brucellosis almost certainly caused by $B$. canis was made. However, she refused long-term antibiotic therapy, as she only had mild malaise. Subsequently, we ob- served her as an outpatient. In January 2017, the high fever recurred. Blood and bone marrow samples were collected, and streptomycin (SM) and doxycycline (DOXY) combination therapy was initiated. Results of culture test and polymerase chain reaction (PCR) for Brucella (target genes; bcsp 31, omp2, and omp31) using both blood and bone marrow were negative, while SAT for B. canis remained positive (1: 160). In addition, antibodies to $Q$ fever were not detected.

After treatment with intramuscular injections of SM (1 g $1 \times / \mathrm{d}$; weeks 1-3) and oral DOXY (100 mg 2x/d; weeks 112 ), her symptoms subsided, and the SAT titer decreased to 1:20 (Fig. 3). Pelvic and spinal magnetic resonance imaging findings were normal. The final diagnosis was chronic brucellosis caused by B. canis infection without an obvious fo- 
cus. Her malaise and fever resolved and had not recurred 18 months after treatment completion. Her Pomeranian dog tested negative for SAT. We concluded that the disease duration was at least two years since 2014. There was a possibility that her disease had been transmitted from the previous dog she had owned between 1999 and 2015. However, we presumed that she had been infected at school, giving a disease duration of 19 years (since 1998), because her medical history suggested completely typical chronic brucellosis.

\section{Discussion}

We herein report a domestic case of chronic brucellosis presumed to be $B$. canis infection with a 19-year disease duration. Human brucellosis is most often caused by $B$. melitensis (major hosts: sheep and goats), B. abortus (cattle), B. suis (swine), and B. canis (dog). Most human cases worldwide are attributed to $B$. melitensis and $B$. abortus (1-3). In Japan, B. suis and B. abortus have already been eradicated, and infections caused by $B$. melitensis have never been observed in domestic animals. Therefore, in recent years, reported brucellosis patients infected with $B$. melitensis and B. abortus are imported cases from endemic countries.

Regarding B. canis infection, recent cases have been considered domestic (2), as the prevalence of B. canis in dogs in Japan is currently around 3\% (4). B. canis is transmitted from dogs to humans mainly via inhalation of contaminated dust or aerosols during delivery or abortion $(2,3)$. As mentioned above, we presumed that our patient had been infected at school. In a 2014 US report, $3.6 \%$ of asymptomatic adults with occupational exposure to dogs were seropositive (5). B. canis infection is usually mild or asymptomatic and does not commonly cause chronic disease $(3,5)$. However, our case indicates that it can be persistently symptomatic for long years. Many human chronic cases with mild symptoms may be underdiagnosed.

At the first febrile episode, the patient presented with the left arm paralysis, and at the last, without obvious focus. Symptoms of brucellosis are nonspecific and various, and the severity ranges from asymptomatic to fatal disease. Acute brucellosis is marked by a fever, night sweats, arthralgia, myalgia, low-back pain, weight loss, malaise, headache, anorexia, and, occasionally, cough, chest pain, and abdominal pain. Chronic brucellosis may present without evidence of infection; the patient may only experience a low-grade fever, malaise, back pain, or psychiatric symptoms $(2,3,6,7)$. Osteoarticular, gastrointestinal, genitourinary, hepatobiliary, pulmonary, neurological, cardiovascular, ocular, and dermatologic involvements are observed in brucellosis $(2,3,8)$. In our case, the left arm paralysis that occurred in 1998 was probably a neurological manifestation. Her fever, persisting for years, was undulant, intermittent, and nocturnal. This fever pattern is typical for brucellosis $(2,3)$, providing us with an important diagnostic clue.

The presumptive disease duration of our case was 19 years, which is relatively long, even in endemic countries. Chronic brucellosis is generally defined as clinical symptoms persisting for $\geq 12$ months. The longest commonly reported disease duration is $<5$ years $(9,10)$. However, one study reported a case with a 57-year duration (11). Brucella is thought to suppress immunity, autophagy, and apoptosis through various mechanisms and can survive long-term intracellularly (12). In Japan, only a few cases of chronic brucellosis have been reported, and none has been reported since 1954 (13-17). To our knowledge, the present case is the first chronic case in 60 years in Japan and the first one to persist for at least 2 years; in addition, it is also the first chronic case presumed to be due to $B$. canis infection.

Our patient tested negative for both culture and PCR using blood and bone marrow, so the diagnosis was based on the SAT. The diagnosis of brucellosis is established via culture, serology, or molecular testing. Cultures are often negative, especially in patients with chronic disease; the diagnosis is therefore made based on the symptoms and results of serological tests $(2,3,8,18)$. While the SAT is the most useful serological tool, the results may be negative in those with chronic disease or an immunocompromised state $(18,19)$. Molecular tests, such as PCR, are considered highly specific; however, their sensitivities reportedly vary $(8,18)$. For instance, one study reported $100 \%$ sensitivity of PCR targeting $b s c p 31$, omp 2 , and $b p 26$ for diagnosing acute disease (20), while another reported only $3 \%$ sensitivity of PCR targeting IS711 for diagnosing chronic or relapsed disease (21). Such discrepancies might be due to the use of different DNA detection methods and different types of specimens. In addition, many other factors, such as the disease definition, disease phase (acute, chronic, or relapsed), and history of antibiotic therapy, vary in these studies.

The first-line treatment regimen for uncomplicated brucellosis is DOXY plus SM or gentamycin. The minimum recommended treatment duration is six weeks $(2,3)$. Combination therapy of DOXY, rifampicin, and ceftriaxone is recommended for neurobrucellosis (22). In our case, we chose DOXY plus SM because none of the findings in 2014-2017 suggested neurological involvement.

\section{Conclusion}

We encountered a case of presumptive B. canis symptomatic infection persisting for many years. Brucellosis should be suspected in cases of chronic fatigue or a fever, even in non-endemic areas. However, many cases remain underdiagnosed or neglected.

The authors state that they have no Conflict of Interest (COI).

\section{References}

1. World Health Organization. The Special Programme for Research and Training in Tropical Diseases (TDR) 2012. Research priorities for zoonoses and marginalized infections [Internet]. [cited 2019 Feb 1]. Available from: http://www.who.int/tdr/publications/zoonos 
es/en/

2. Imaoka K. Review: Brucellosis. JBSA Newsletter vol. 17, No. 1, 2018 May (in Japanese) [Internet]. [cited 2019 Feb 10]. Available from: https://www.microbiology.co.jp/jbsa/information/2017/newsle tter_vol7_1.pdf

3. WHO/CDS/EPR/2006.7. Brucellosis in humans and animals [Internet]. [cited 2019 Feb 3]. Available from: http://www.who.int/csr/r esources/publications/deliberate/WHO_CDS_EPR_2006_7/en/

4. Tachibana M, Kobayashi N, Inokuma H, Suzuki H, Watarai M. Seroepidemiological survey of Brucella canis infection in dogs in Japan using the tube agglutination test. J Jpn Vet Med Assoc 64: 559-561, 2011.

5. Krueger WS, Lucero NE, Brower A, Heil GL, Gray GC. Evidence for unapparent Brucella canis infections among adults with occupational exposure to dogs. Zoonoses Public Health 61: 509-518, 2014.

6. Scarlett EP. Chronic brucellosis; diagnosis and treatment. Can Med Assoc J 58: 230-235, 1948.

7. McDevitt DG. Symptomatology of chronic brucellosis. $\mathrm{Br} \mathrm{J}$ Ind Med 30: 385-389, 1973.

8. Franco MP, Mulder M, Gilman RH, Smits HL. Human brucellosis Lancet Infect Dis 7: 775-786, 2007.

9. Yumuk Z, O'Callaghan D. Brucellosis in Turkey - an overview. Int J Infect Dis 16: e228-e235, 2012.

10. Geyik MF, Gür A, Nas K, et al. Musculoskeletal involvement of brucellosis in different age groups: a study of 195 cases. Swiss Med Wkly 132: 98-105, 2002.

11. Griggs JF. Chronic brucellosis: diagnostic points noted in one hundred cases. Cal West Med 58: 118-125, 1943.

12. Ahmed W, Zheng K, Liu ZF. Establishment of chronic infection: Brucella's stealth strategy. Front Cell Infect Microbiol 6: 30, 2016.
13. Nishikawa J. A case of Bang's disease in Japan. Tokyo Iji Shinshi 2843: 23-24, 1933 (in Japanese).

14. Nakagawa H. A case of Bang's disease. Jikken Ihou 20: 907-911, 1934 (in Japanese).

15. Kakinuma K, Yamakawa K. Brucellosis. Jikken Ihou 28: 661-665, 1941 (in Japanese).

16. Nao Y, Tachi T. Clinical experience of brucellosis. Rinshou Naika Shounika 5: 72-75, 1950 (in Japanese).

17. Imanaka K, Kobayashi I. Spinal brucellosis. Geka no Ryouiki 2: 293-298, 1954 (in Japanese).

18. Araj GF. Update on laboratory diagnosis of human brucellosis. Int J Antimicrob Agents 36S: S12-S17, 2010.

19. Galińska EM, Zagorski J. Brucellosis in humans - etiology, diagnostics, clinical forms. Ann Agric Environ Med 20: 233-238, 2013.

20. Mitka S, Anetakis C, Souliou E, Diza E, Kansouzidou A. Evaluation of different PCR assays for early detection of acute and relapsing brucellosis in humans in comparison with conventional methods. J Clin Microbiol 45: 1211-1218, 2007.

21. Alsayed Y, Monem F. Brucellosis laboratory tests in Syria: what are their diagnostic efficacies in different clinical manifestations? J Infect Dev Ctries 6: 495-500, 2012.

22. Erdem H, Ulu-Kilic A, Kilic S, et al. Efficacy and tolerability of antibiotic combinations in neurobrucellosis: results of the Istanbul study. Antimicrob Agents Chemother 56: 1523-1528, 2012.

The Internal Medicine is an Open Access journal distributed under the Creative Commons Attribution-NonCommercial-NoDerivatives 4.0 International License. To view the details of this license, please visit (https://creativecommons.org/licenses/ by-nc-nd/4.0/).

(C) 2019 The Japanese Society of Internal Medicine Intern Med 58: 3179-3183, 2019 